\title{
Effect of Experimental Ricinus communis Solution for Denture Cleaning on the Properties of Acrylic Resin Teeth
}

\author{
Marina Xavier PISANI \\ Ana Paula MACEDO \\ Helena de Freitas Oliveira PARANHOS \\ Cláudia Helena Lovato da SILVA \\ Department of Dental Materials and Prosthodontics, Ribeirão Preto Dental School, \\ USP -University of São Paulo, Ribeirão Preto, SP, Brazil
}

\begin{abstract}
This study evaluated Knoop hardness, surface roughness and color alteration of artificial teeth for dentures after immersion in water, $1 \%$ sodium hypochlorite and an experimental solution of $2 \%$ Riccinus communis (RC). Thirty specimens of Vipi, Biolux and Trilux were analyzed. Tests of Knoop hardness, surface roughness and color alteration were conducted immediately after specimen preparation (T0) and after two immersion protocols for 15 days $\left(\Delta \mathrm{T}^{15}\right)$ and 183 days $\left(\Delta \mathrm{T}^{183}\right)$. Data variation $(\Delta \mathrm{T})$ were subjected to ANOVA and Tukey's test $(\mathrm{p}<0.05)$. At $\Delta \mathrm{T}^{15}$, Vipi presented hardness increase and Biolux presented the highest variation $(\mathrm{p}=0.01)$. $\mathrm{RC}$ caused the highest increase in hardness $(p=0)$ and the lowest increase $(p=0.005)$ in roughness. Biolux presented the lowest color alteration $(p$ $=0)$. At $\Delta \mathrm{T}^{183}$, Trilux underwent the highest hardness variation $(\mathrm{p}=0)$. Biolux presented an increase in roughness $(\mathrm{p}=0)$. There was no significant differences in color alteration among the artificial teeth $(\mathrm{p}=0.06)$ and among solutions $(\mathrm{p}=0.08)$ after 183 days of immersion All solutions (distilled water, $1 \%$ sodium hypochlorite and $2 \% \mathrm{RC}$ ) caused alterations on the analyzed properties. Both immersion protocols caused alterations on the analyzed properties.
\end{abstract}

Key Words: denture cleanser, Ricinus communis, acrylic denture teeth.

\section{INTRODUCTION}

Denture cleansing is important to increase denture longevity, maintain the health of oral mucosa and improve patient's quality of life. Chemical disinfectants for immersion have been widely used as denture cleansers. It is essential that these cleansers have bactericidal and fungicidal properties and effectively remove organic and inorganic matter from denture surface (1). Another important consideration is that the mechanical and physical properties of the acrylic resin and artificial denture teeth should remain unaltered after denture cleansing. However, it has been shown that some disinfectant solutions cause alterations in physical and mechanical properties of denture base resins $(2,3)$ and artificial teeth (4). Some components of these solutions can penetrate into the material and not be completely eliminated by rinsing (5).
New formulations of denture cleansers are welcome because until now an ideal denture cleanser is not available. The World Health Organization has encouraged the search for substances and products derived from animal, vegetal and mineral sources. Many plants are known for their medical and antimicrobial properties and the efforts have been directed towards the search of alternative and low cost cleaning products that could be safely used by the population. One of these plants is Ricinus communis or castor plant (division Magnoliophyta, class Magnoliopside, sub-class Rosidae, order Euforbiales, family Euforbiaceae), which is a vegetal typically found in tropical climate areas. Because of its climatic characteristics, Brazil has one of the largest areas cultivated with Ricinus communis in the world (6).

The oil extracted from the Ricinus communis seeds is used in the production of a detergent. In Endodontics, this detergent has been tested as an

Correspondence: Profa. Dra. Cláudia Helena Lovato da Silva, Departamento de Materiais Dentários e Prótese, Faculdade de Odontologia de Ribeirão Preto, Universidade de São Paulo, Avenida do Café s/n, 14040-904 Ribeirão Preto, SP, Brasil. Tel: +55-16-3602-4006. email: chl@forp.usp.br 
irrigating solution and has shown biocompatibility to periapical tissues and antimicrobial, bactericidal and antiinflammatory activity similar to sodium hypochlorite (NaOCl) (7). The Ricinus communis detergent acts by breaking sugar leakage of the cellular wall of pathogenic microorganisms, consequently the loss of cytoplasmic material leads to cell destruction $(7,8)$. Based on this, an experimental solution of $2 \%$ Ricinus communis has been developed to be used as a denture cleanser. In addition to its antimicrobial and cleaning potential, it is important to analyze whether this solution can affect the properties of denture components, such as the acrylic denture teeth.

Three important properties to be analyzed are hardness, surface roughness and color change of acrylic denture teeth. Hardness has been used as a measurement to predict wear resistance (9), roughness is related to biofilm adhesion (10) and color change is related to aesthetics and is an indicative of the serviceability of the material (11). Therefore, the aim of this study was to evaluate the effect of $2 \%$ Ricinus communis solution on Knoop hardness, surface roughness and color change of three brands of acrylic resin denture teeth compared with $1 \% \mathrm{NaOCl}$ after two immersion protocols. The null hypothesis tested is that $2 \%$ Ricinus communis has no effect on the hardness, roughness and color change of the acrylic resin denture teeth.

\section{MATERIAL AND METHODS}

\section{Specimen Preparation and Groups}

Three commercially available brands of acrylic resin denture teeth were used; their names and bath numbers are presented in Table 1 . The maxillary central incisor of largest size of each brand was selected to establish a standard for comparison and because these teeth are located in an esthetic region of the mouth.

The artificial teeth had their palatal face flattened with a sequence of 180-, 220-, 360and 400-grit silicon carbide papers (Norton - Saint-Gobain Abrasivos Ltda., Guarulhos, SP, Brazil). The buccal face was not altered. Surface roughness and Knoop hardness tests needed a flat surface because the indentor tip for both tests must be perpendicular to the surface to be analyzed. According to the manufacturers, the denture teeth tested have a uniform composition. It was assumed that no difference existed between hardness of the surface layer and the worn palatal surface (4). Moreover, it is important to analyze the inner surface, as the outer surface or enamel layer of denture teeth is often removed due to many reasons, such as masticatory wear, or mostly occlusal adjustments or alterations of the occlusal scheme by the dentist (9). The color change was measured on the buccal face instead of the palatal face because aesthetics is important in this area.

The thickness in the cervical, middle and incisal areas was $4 \mathrm{~mm}, 3.3 \mathrm{~mm}$ and $2 \mathrm{~mm}$, respectively, as confirmed with an electronic caliper (CD-6" CSX-B; Mitutoyo South American Ltda., Suzano, SP, Brazil).

Ninety specimens, 30 of each brand, were randomly assigned to 3 groups of immersion in 200 $\mathrm{mL}$ of the solutions: Negative control group (distilled water at $\left.37^{\circ} \mathrm{C}\right)$; positive control group $(1 \% \mathrm{NaOCl}$; Asfer Chemistry Ind. Ltda, São Paulo, SP, Brazil) and experimental group (2\% Ricinus Communis solution, Chemistry Institute, University, São Carlos, SP, Brazil).

\section{Experimental Period}

The hardness, roughness and color were assessed immediately after specimen preparation (baseline) and after different immersion periods. The specimens were immersed in each of the three solutions for 15 consecutive days to simulate 3 years following a denture cleansing regimen of $20 \mathrm{~min}$ daily $\left(\Delta \mathrm{T}^{15}\right)(2)$. After this period, new tests of color, hardness and roughness were conducted. The specimens were then immersed for 183 consecutive days $\left(\Delta \mathrm{T}^{183}\right)$ to simulate 1.5 year of use following a regimen of $8 \mathrm{~h}$ (overnight) daily (2). After this period, new tests were performed. The immersion solutions were changed once a day for both protocols.

Table 1. Acrylic resin denture teeth.

\begin{tabular}{lccc}
\hline $\begin{array}{l}\text { Commercial } \\
\text { brand }\end{array}$ & Model & Manufacturer & $\begin{array}{c}\text { Batch } \\
\text { number }\end{array}$ \\
\hline VipiDent Plus & $\begin{array}{c}28 \\
\text { Color: } 66\end{array}$ & $\begin{array}{c}\text { Dental Vipi Ltda, } \\
\text { Pirassununga, SP, Brazil }\end{array}$ & 6501 \\
Biolux & V17 & $\begin{array}{c}\text { Dental Vipi Ltda, } \\
\text { Color: } 66\end{array}$ & $\begin{array}{c}\text { Pirassununga, SP, Brazil } \\
\text { E5 }\end{array}$ \\
Trilux & $\begin{array}{c}\text { Ruthinium Group Badia } \\
\text { Polesine, Rovigo Italy }\end{array}$ & 6600 \\
\hline
\end{tabular}




\section{Analysis of Knoop Hardness and Surface Roughness}

Knoop hardness was measured with a Shimadzu microhardness tester (model HMV-2; Shimadzu Corporation, Kyoto, Japan) with a load of $25 \mathrm{~g}$ for $5 \mathrm{~s}$. The roughness test was performed using roughness tester (SJ-201P; Mitutoyo Corp, Kawasaki, Japan).

For both tests, teeth were fixed on a \#9 wax plate (Lysanda Inc., Presidente Prudente, SP, Brazil). The palatal face was stable and perpendicular to the Knoop and roughness indentor tip. The surface of each specimen was divided into three equal parts and three measurements were made in each part to obtain the mean.

\section{Analysis of Color Change}

For color measurements of acrylic resin teeth, a reference mark was used for placing the measuring port of the instrument on the same location on the specimen for repeated measures, and a silicone device was developed (Zetalabor Zhermack, Rovigo, Italy) for inserting the specimen insertion in the spectrocolorimeter opening. The spectrocolorimeter (BYK-Gardner GmbH - 07/2002, Geretsried, Germany) was calibrated according to the manufacturer's instructions before each measurement period using the white calibration cap supplied by the manufacturer. Color change $(\Delta \mathrm{E})$ were calculated by measuring tristimulus values using the CIE L*a*b* Color Scale.

\section{Data Analysis}

Statistical analysis of hardness, roughness and color change was carried out SPSS statistical software (SPSS Inc., Chicago, IL, USA).

Variation of hardness and roughness data at both evaluation periods was calculated by subtracting the values obtained after immersion for 15 days $\left(\Delta T^{15}\right)$ and 183 days $\left(\Delta \mathrm{T}^{183}\right)$, respectively, from those obtained at baseline. Therefore, negative values represented a reduction and positive values an increase of the variable. A two-way ANOVA was performed using materials and immersion solutions as independent factors. Multiple comparisons were done by Tukey's test ( $\alpha=0.05)$.

\section{RESULTS}

Comparisons among means and the respective standard deviations (SD) are presented in Figures 1-3.

\section{Knoop Hardness}

For $\Delta \mathrm{T}^{15}$, statistically significant difference was found among the teeth $(\mathrm{p}=0.01)$ and among the solutions $(p=0)$, but not for interactions $(p=0.41)$. Only Vipi presented hardness increase; Biolux and Trilux presented hardness decrease and there were no statistically significant difference among them. Ricinus communis solution caused hardness increase; distilled water and $\mathrm{NaOCl}$ caused hardness decrease (Fig. 1).

For $\Delta T^{183}$, there was statistically significant difference among teeth $(\mathrm{p}=0)$ and among the solutions $(\mathrm{p}=0.01)$, but not for interactions $(\mathrm{p}=0.15)$. All tooth brands underwent hardness decrease. Trilux differed significantly from Vipi and Biolux, and presented the highest hardness variation. All solutions caused hardness decrease. Ricinus communis solution was significantly different from distilled water and $\mathrm{NaOCl}$, and caused the smallest hardness variation (Fig. 1).

\section{Surface Roughness}

For $\Delta \mathrm{T}^{15}$, statistically significant difference was found only among the solutions $(\mathrm{p}=0.005)$. Ricinus communis solution caused roughness increase. Distilled water and $\mathrm{NaOCl}$ caused roughness decrease and were statistically similar (Fig. 2).

$\Delta T^{183}$, significant differences were found only among the teeth $(\mathrm{p}=0)$. Vipi and Trilux presented decrease of roughness. Biolux was statistically different from Vipi and Trilux, and presented increase of roughness (Fig. 2).

\section{Color Change}

For $\Delta \mathrm{T}^{15}$, significant differences were found only among the teeth $(\mathrm{p}=0)$, where Biolux presented the smallest color change. For $\Delta \mathrm{T}^{183}$, there were no statistically significant differences among the teeth $(\mathrm{p}=0.06)$, solutions $(\mathrm{p}=0.08)$ or significant interactions $(\mathrm{p}=0.16)$ (Fig. 3).

\section{DISCUSSION}

The present study evaluated the effect of $2 \%$ Ricinus communis solution on hardness, roughness and color change of three brands of acrylic resin denture teeth in comparison with $1 \% \mathrm{NaOCl}$ and distilled water as a control group. The null hypothesis was rejected as all solutions caused some alteration on the physical and 
mechanical properties analyzed.

The acrylic denture teeth used in this study are composed of PMMA (polymethyl metracrylate) and EDMA(dimethacrylate of polymerized ethylene glycol), which is a cross-linking agent. An optimal amount of cross-linking can improve the mechanical properties of acrylic resin denture teeth, reducing the tendency to craze (form pre-cracks) under stress and the solubility to organic solvents (12). Trilux artificial teeth have triple press (incisal, cervical and dentin), are made of acrylic resin of high molecular weight combined with the use of double cross-linking (DCL) system and have organic modified ceramics (Ormocer ${ }^{\circledR}$ ). Biolux teeth have double press (body and enamel) and are made of polymer of high molecular weight combined with the use of DCL. Vipi teeth have double press (body and enamel) and a

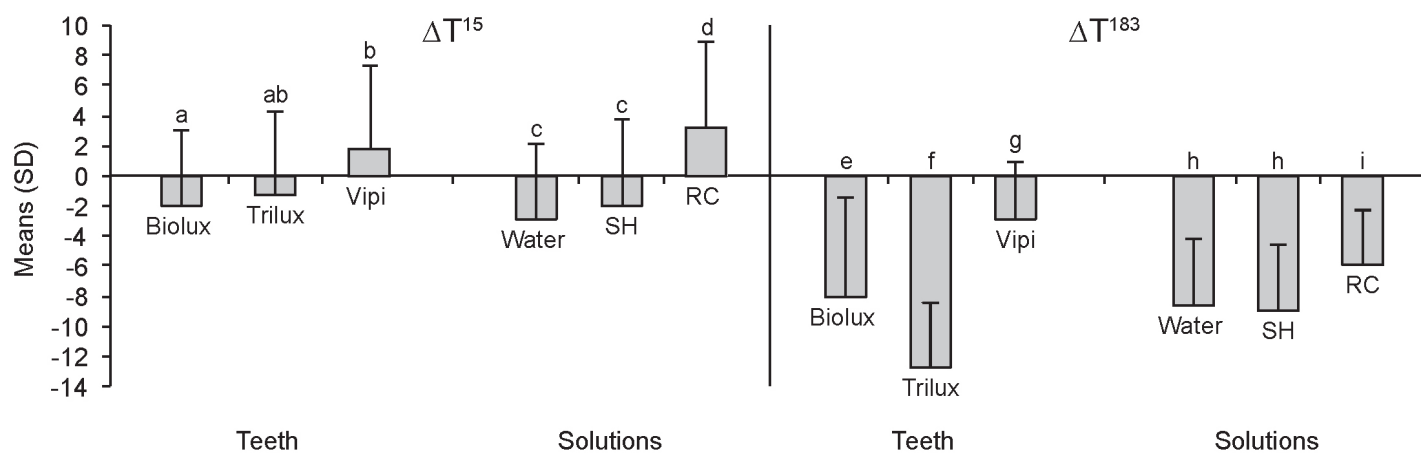

Figure 1. Comparison of means (SD) of Knoop hardness for $\Delta \mathrm{T}^{15}$ and $\Delta \mathrm{T}^{183}$. Different letters indicate statistically significant difference at $0.05 . \mathrm{SH}=$ sodium hypochlorite; $\mathrm{RC}=$ Ricinus communis.

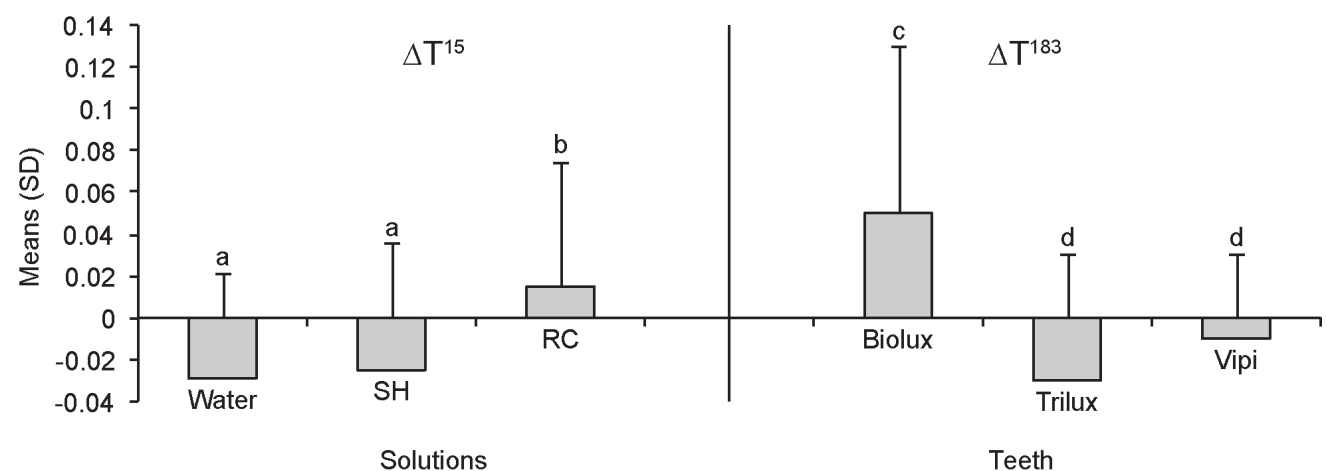

Figure 2. Comparison of means (SD) of roughness for $\Delta \mathrm{T}^{15}$ (solutions) and $\Delta \mathrm{T}^{183}$ (teeth). Different letters indicate statistically significant difference at $0.05 . \mathrm{SH}=$ sodium hypochlorite; $\mathrm{RC}=$ Ricinus communis.

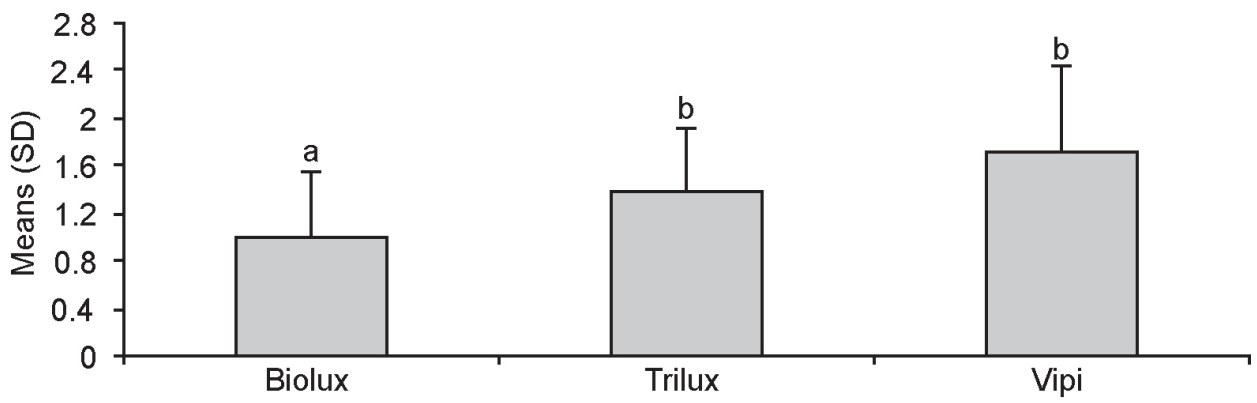

Figure 3. Comparison of means (SD) of color alteration $(\Delta \mathrm{E})$ of the artificial teeth for $\Delta \mathrm{T}^{15}$. Different letters indicate statistically significant difference at 0.05 . 
linear and not interpenetrate polymer chain.

There are in the literature few studies analyzing the effects of denture cleansers in artificial denture teeth $(4,13)$. The effects of $2 \%$ Ricinus communis solution in mechanical and physical properties of denture acrylic resin (2) and denture liners (14) have already been investigated using the same cleansing protocols of the present study. In acrylic resins, the Ricinus communis solution caused alterations on the properties and was not superior to $1 \% \mathrm{NaOCl}$ (2). However, the Ricinus communis solution had less effect on the properties of silicone-based denture liners compared to $1 \% \mathrm{NaOCl}$ (14). The observation of the effect of denture cleaners after long period of use ( 3 years and 1.5 year) is also important because patients rarely change their prosthesis before this period. The regimens used were $15 \mathrm{~min}$ daily immersion and overnight daily immersion; both recommended procedures by the dentists to their patients $(2,14)$.

The results regarding Knoop hardness showed for $\Delta \mathrm{T}^{15}$ (Fig. 1) that Biolux and Trilux underwent hardness decrease, while Vipi underwent hardness increase and Ricinus communis solution was the main responsible for the hardness increase in comparison with the baseline values. The hardness increase for Vipi can be explained, perhaps, by the fact that they are less resistant to the loss of plasticizers and do not have DCL chains, which reduce their resistance.

After simulation of 1.5 year of overnight immersion $\left(\Delta T^{183}\right)$, all tooth brands presented a decrease in hardness (Fig. 1); Trilux underwent the highest reduction, followed by Biolux and Vipi. These results are in accordance with those of Campanha et al. (4) who also worn the occlusal teeth surface and found a reduction in hardness of Trilux after immersion for 7 days in $1 \% \mathrm{NaOCl}$ The Ricinus communis solution caused the lowest hardness reduction after this period of immersion (Fig. 1). Pavarina et al. (13) found that the immersion in distilled water decreased hardness of the acrylic denture teeth tested. The absorption of water and aqueous cleansers such as $\mathrm{NaOCl}$ and Ricinus communis caused reduction in hardness due to the fact that these solutions could act as plasticizers. Similar to what happens with acrylic resin, in denture teeth basically composed of the same material, small molecules of water diffuse into the polymer mass and cause the relaxation of polymer chains, consequently reducing the hardness of artificial teeth (15). Probably, microcracks formed during the wear of the palatal face could have facilitated the infiltration of solutions, accelerating the process of PMMA plasticizing (16).

Teeth composed by double cross-linked agents should promote, in theory, a decrease in fluid diffusion to the polymer because of their inseparable chains and higher resistance. However, Trilux teeth showed the highest reduction in hardness for $\Delta \mathrm{T}^{183}$ (Fig. 1), perhaps due to some intrinsic factor related to their composition or their triple press. For polymer based materials, there may be also several other factors that may influence the hardness values including time and speed of elastic recovery (12).

For $\Delta \mathrm{T}^{15}$, there was no roughness difference among the tooth brands, only among the solutions. (Fig. 2). The $2 \%$ Ricinus communis solution caused an increase in roughness (Fig. 2), while distilled water and $\mathrm{NaOCl}$ caused reduction in this property. Pisani et al. (2) also found roughness increase in acrylic resins after immersion in Ricinus communis and attributed this result to a tick and sticky film formed on specimen surface. In Endodontics, the use of Ricinus communis solution as an as irrigant increased root canal dentin permeability due to its low superficial tension and the moisturizing capacity, which increases the contact of the solution with tooth surface $(6,7)$. Although this consideration is not related to acrylic denture teeth, it is necessary to investigate the action of this solution on the permeability and degradation of organic matrix present in artificial teeth, which could represent an increase in roughness. Additional studies concerning the mechanism of action of Ricinus communis solution should be developed in the future.

For $\Delta \mathrm{T}^{183}$ (Fig. 2), only Biolux presented roughness increase, regardless the solution. After immersion in solutions, Biolux teeth were less resistant to the action of solvents, which may have allowed the loss of components such as plasticizers and exposure of the layers polished with smaller grain sandpapers, creating porosities in the polymer mass, which could be representative of an increase in roughness.

For $\Delta \mathrm{T}^{15}$ (Fig. 3), Biolux showed smaller color change compared with Vipi and Trilux. There was no significant difference among distilled water, $\mathrm{NaOCl}$ and $2 \%$ Ricinus communis solution. Color change can occur due to extrinsic or intrinsic factors $(11,17)$. Extrinsic factors, such as absorption and adsorption, can cause discoloration (11). According to Anil et al. (17), other factors are also related to color change, such as stain dehydration, water absorption, leakage, rough 
surfaces, chemical and aging degradation, oxidation during the double reaction of carbon-producing peroxide composites, and permanent formation of pigments following product degradation. The intrinsic factors are related to the chemical stability of the material and oxidation of the polymer matrices (17).

Having more discoloration in one substance than in another is due to the various pigmentations present in the characterization of teeth and absorption and adsorption of solutions. Hydrophilic components, such as HEMA, generally exhibit a greater color change than hydrophobic materials $(9,12)$. Acrylic resin teeth composed by PMMA have a high conversion rate and a low quantity of additional reagents, such as dibenzoyl peroxide, that remain after the reaction and may cause color instability (12). Biolux teeth presented less color change. These teeth are probably fabricated with a more hydrophobic monomer liquid, which absorb less amount of solution are thus esthetically favorable. The low susceptibility to staining is related to low solution sorption $(11,12)$. Therefore, Vipi and Trilux teeth may present lower solubility than the others, resulting in higher values than Biolux for $\Delta \mathrm{T}^{15}$.

For $\Delta \mathrm{T}^{183}$, there was no significant difference among the solutions or among the teeth, so the presence of cross-linked agents may have prevented changes due to the resistance to solvents (12). $\Delta \mathrm{E}$ value above 3.3 is clinically perceptible and unacceptable (18). In the present study, all color changes observed in the denture teeth were below this value, representing lack of visible color change.

According to Robinson et al. (19), the different layers of acrylic resin artificial teeth are affected in different degrees of intensity for solutions and there is a modification of the interstitial matrix. Surface clarity and color of the object may influence color determination (20). Thickness and smoothness of the specimen surface can also influence color evaluation (20). Kanie et al. (20) observed that the luminosity of acrylic resin decreases as the material thickness increases.

One of the limitations of this study is that there are some methodological problems for the detection of color change in artificial teeth once that the oral environment is hardly reproduced and spectrocolorimeter can spread the light in different directions because the buccal face is not flat. Moreover, few reports were found in the literature using acrylic denture teeth $(4,13)$ and Ricinus communis $(2,14)$ for comparison of results. Also, to overcome the limitations of in vitro tests, the color change of acrylic resin denture teeth should be evaluated intraorally. It is important to point out that alterations did occur, but the mean values were within the acceptable limits for roughness, hardness and color change.

In conclusion, the solutions (distilled water, $1 \% \mathrm{NaOCl}$ and Ricinus communis) and the protocols of immersion $\left(\Delta \mathrm{T}^{15}\right.$ and $\left.\Delta \mathrm{T}^{183}\right)$ caused alterations on the hardness, roughness and color of the acrylic resin denture teeth.

\section{RESUMO}

Este estudo avaliou a dureza Knoop, rugosidade e alteração de cor de dentes artificiais após imersão em água, hipoclorito de sódio $1 \%$ e solução de Ricinus communis $2 \%$ (RC). Trinta espécimes de dentes das marcas Vipi, Biolux e Trilux foram analisados. Os testes de dureza, rugosidade e alteração de cor foram realizados após a obtenção dos espécimes (T0) e após dois protocolos de imersão nas soluções por 15 dias $\left(\Delta^{15}\right)$ e 183 dias $\left(\Delta^{183}\right)$. A variação dos dados $(\Delta \mathrm{T})$ foi submetida à ANOVA e teste de Tukey $(p<0,05)$. Em $\Delta T^{15}$, Vipi apresentou aumento da dureza e Biolux, a maior variação $(p=0,01)$. RC causou o maior aumento na dureza $(p=0)$. RC causou o menor aumento na rugosidade $(p=0,005)$. Biolux apresentou a menor alteração de cor $(p=0)$. $\operatorname{Em} \Delta \mathrm{T}^{183}$, Trilux apresentou a maior variação na dureza. $(\mathrm{p}=0)$. Biolux apresentou aumento na rugosidade $(p=0)$. Não houve diferença significante na alteração de cor entre dentes $(\mathrm{p}=0,06)$ e entre soluções $(p=0,08)$ após 183 dias de imersão. Todas as soluções (água destilada, hipoclorito de sódio 1\% e RC) causaram alterações nas propriedades analisadas. Ambos os protocolos de imersão causaram alterações nas propriedades analisadas.

\section{ACKNOWLEDGEMENTS}

The authors wish to thank Dr. Gilberto Chiérese for providing the Ricinus communis solution.

\section{REFERENCES}

1. Felipucci DN, Davi LR, Paranhos HF, Bezzon OL, Silva RF, Pagnano VO. Effect of different cleansers on the surface of removable partial denture. Braz Dent J 2011;22:392-397.

2. Pisani MX, Silva CHL, Paranhos HFO, Souza RF, Macedo AP. The effect of experimental solution Ricinus communis on acrylic resin acrylic properties. Mater Res 2010;13:369-373.

3. Peracini A, Davi LR, de Queiroz Ribeiro N, de Souza RF, Lovato da Silva CH, de Freitas Oliveira Paranhos H. Effect of denture cleansers on physical properties of heat-polymerized acrylic resins. J Prosthodont Res 2010;54:78-83.

4. Campanha NH, Pavarina AC, Jorge JH, Vergani CE, Machado AL, Giampaolo ET. The effect of long-term disinfection procedures on hardness properties of resin denture teeth. Gerodontology 2011. (doi: 10.1111/j.1741-2358.2011.00520.x).

5. Campanha NH, Pavarina AC, Vergani CE, Machado AL. Effect of microwave sterilization and water storage on the Vickers hardness of acrylic resin denture teeth. J Prosthet Dent 2005;93:483-487.

6. Meneghin MP, Nomelini SMB, Sousa-Neto MD, Marchesan MA, França SC, dos Santos HSL. Morphologic and morphometric 
analysis of the root canal apical third cleaning after biomechanical preparation using 3.3\% Ricinus communis detergent and 1\% $\mathrm{NaOCl}$ irrigating solutions. J Appl Oral Sci 2006;14:178-182.

7. Ferreira CM, Bonifacio KC, Froner IC, Ito IY. Evaluation of the antimicrobial activity of three irrigation solutions in teeth with pulpal necrosis. Br Dent J 1999;10:15-21.

8. Ito I, Froner IC, Mian H, Chierece GO. Castor oil: antimicrobial activity of detergent derived from ricinolic acid. J Dent Res 1999; 78:344-345.

9. Suwannaroop P, Chaijareenont P, Koottathape N, Takahashi H, Arksornnukit M. In vitro wear resistance, hardness and elastic modulus of artificial denture teeth. Dent Mat J 2011;30:461-468.

10. Bollen CML, Lambrechts P, Quiryen M. Comparison of surface roughness of oral hard materials to the threshold surface roughness for bacterial plaque retention: a review of the literature. Dent Mat 1997; 13:258-269.

11. Jin C, Nikawa $H$, Makihira $S$, Hamada $T$ and Furukawa $M$. Changes in surface roughness and colour stability of soft denture lining materials caused by denture cleansers. J Oral Rehabil 2003;30:125-130.

12. Assunção WG, Barão VAR, Pita MS, Goiato MC. Effect of polymerization methods and thermal cycling on color stability of acrylic resin denure teeth. J Prosthet Dent 2009;102:385-392.

13. Pavarina AC, Vergani AC, Vergani CE, Machado AL, Giampaolo T, Teraoka MT. The effect of disinfectant solutions on the hardness of acrylic resin denture teeth. J Oral Rehabil 2003;30:749-752.

14. Pisani MX, Silva-Lovato CH, Paranhos HFO, Souza RF, Macedo AP. Evaluation of experimental cleanser of Ricinus communis: effect on soft denture liner properties. Gerodontology 2010 (doi: 10.1111/j.1741-2358.2010.00438.x).
15. Braun KO, Mello JA, Rached RN, Del Bel Cury AA. Surface texture and some properties of acrylic resins submitted to chemical polishing. J Oral Rehabil 2003;30:91-98.

16. Assunção WG, Gomes EA, Barão VAR, Barbosa DB, Delben JA, Tabata LF. Effect of storage in artificial saliva and thermal cycling on Knoop hardness of resin denture teeth. J Prosthodont Res 2010;54:123-127.

17. Anil N, Hekimoglu C, Buyukbas N, Ercan MT. Microleakage study of various soft denture liners by autoradiography: effect of accelerated aging. J Prosthet Dent 2000;84:394-399.

18. Mutlu-Sagesen L, Ergun G, Ozkan Y, Semiz M. Color stability of a dental composite after immersion in various media. Dent Mater J 2005;24:382-390.

19. Robinson JG, McCabe JF, Storer R. The whitening of acrylic dentures: the role of denture cleansers. Br Dent J 1985;159:247250.

20. Kanie T, Arikawa H, Fujii K, Inoue K. Physical and mechanical properties of PMMA resins containing gamma-methacryloxyprop yltrimethoxysilane. J Oral Rehabil 2004;31:166-171.

Received May 25, 2011 Accepted November 17, 2011 